\title{
Impact of Tailored Educational Program on Primigravida Anxiety and Knowledge Regarding Minor Discomforts in Upper Egypt
}

\author{
Hanan Elzeblawy Hassan ${ }^{1}$, Walaa Fathy Mohamed Ahmed ${ }^{2} \&$ Alyaa Abdallah Mahmoud ${ }^{3}$ \\ ${ }^{1}$ Department of Maternal and Newborn Health Nursing, Faculty of Nursing, Beni-Suef University, Egypt \\ ${ }^{2}$ Department of Maternity and Gynecological Nursing, Faculty of Nursing, Ain Shams University, Egypt \\ ${ }^{3}$ Department of Psychiatric and Mental Health Nursing, Beni-Suef University, Egypt \\ Correspondence: Hanan Elzeblawy Hassan, Maternal and Newborn Health Nursing, Faculty of Nursing, \\ Beni-Suef University, Egypt.
}

Received: July 19, 2019

Accepted: August 25, 2019

Online Published: January 2, 2020

doi:10.20849/ijsn.v5i1.698

URL: https://doi.org/10.20849/ijsn.v5i1.698

\begin{abstract}
Background: Although minor discomforts are not life-threatening, nevertheless their presence detracts from the mother feeling of comfort and well-being as well as their negligence may lead to serious problems. In many instances, they can be managed by self-care measures or healthful practices ones can do. Aim: evaluate the impact of a tailored educational program on primigravida anxiety and knowledge regarding minor discomforts. Subjects and Methods: A quasi-experimental design was used with a purposive sample of 50 primigravida pregnant women, suffering from minor disorders of pregnancy attending to the outpatient antenatal care units affiliated to Beni-Suef Public Hospital in Beni-Suef city, Egypt. A structured-knowledge-questionnaire, Zung's-self-rating-anxiety-scale, and pre/post/retained-knowledge-assessment-sheet were used for data collection. Result: The majority of the participant women had poor knowledge with a marked increased severity level of self-rating-anxiety-scale regarding to minor discomfort of pregnancy. There were statistically significant relations between primigravida level of knowledge and their self-rating-anxiety-scale after the educational session and at follow up time compared to there before it ( $p$-value $<0.05$ ). Conclusion: Designing and implementing an educational program about the studied subject indicated a significant effect in a remarkable rising of the primigravida level of knowledge with minimizing their level of anxiety. Recommendations: Based on the findings of this study, provision of the educational guidelines of the minor disorders to the antenatal clinics to be distributed to all the women attending to the clinic is of great value which is prepared in simple Arabic language.
\end{abstract}

Keywords: primigravida, minor discomfort, knowledge, anxiety

\section{Introduction}

Pregnancy for the first time is a special period in a woman's life characterized by rapid physiological, psychological, and social changes during a relatively short period as a result of hormonal effect and adaptation to the gestational process ${ }^{[1]}$. If she is not emotionally supported with surrounding family, relatives and friends as well as if she is not provided with enough and suitable information for this period that may predispose in primigravida women to anxiety. Anxiety during pregnancy is a relatively distinct syndrome which is provoked by specific fears and worries. Anxious pregnant women experience both somatic and emotional symptoms, as well, such as muscle pain, gastrointestinal discomfort, palpitation, worry, and insomnia ${ }^{[2]}$. It has been suggested that high levels of pregnancy-related anxiety may play a role in preterm-birth, postpartum-depression, and caesarean section. Also, it could affect fetal/infant and child development. A variety of issues may provoke anxiety in primigravida women. Among such issues is lack of knowledge concerning minor discomfort, worries about childbirth and health of the baby, quality of care during labor, the extent of husbands' support and involvement in maternal health care, and the level of support from relatives and friends. Most pregnant women complain some degree of minor discomforts ${ }^{[3]}$.

The common pregnancy minor discomforts may be physiological (backache, leg cramps, oedema, constipation, fatigue, nausea and vomiting, sleep disturbance, heartburn, and increased urinary frequency, etc.), or psychosocial (anxiousness, mood swing and lack of family support, etc.). Experiences of these changes are varied 
among pregnant women. These discomforts aren't serious in themselves, but their presence affects and decrease a woman's feeling of wellbeing and comfort. Pregnancy-related minor discomforts can be managed by proper explanation, simple remedies, and lifestyle pattern modification. Consequently, pregnant women should have basic knowledge of common minor discomforts. Also, they should know how to overcome these discomforts during pregnancy. So that they can avoid the complications related to their minor discomforts of pregnancy and they can maintain their health condition. Providing information about physiology, prevention, and self-care of pregnancy discomforts can assist in relieving certain anxiety and fears related to the maternity care is healthy pregnancy with physically safe and emotionally satisfying outcome for mother, infant, and family ${ }^{[4-5]}$.

The ultimate goal of any pregnancy is the birth of a healthy newborn. Many pregnant women rely on nurses to provide accurate information and compassionate guidance throughout their pregnancy. To respond effectively; nurses must understand not only the minor discomforts but also the self-care practices to relieve them. Nurse can play a major and vital role in providing anticipatory guidance to foster the women's responsibility for self-care practices, helping to clarify misconceptions and correct any misinformation. Educating the pregnant mother to identify threats to safety posed by her lifestyle, cultural, social, behavioral condition and environment and proposing ways to modify them to avoid a negative outcome are important. Moreover, nurses must be aware of the types of health-related activities in which pregnant mothers may be engaged. If the nurses are knowledgeable enough about self-care-practices, appropriate referrals may be made that can help pregnant mothers augment their treatments, cope with symptoms and unpleased side effects from treatments, maintain and promote their health. Also, maternity nurses play a crucial role in the quality of antenatal care improvement, which provides pregnant woman education and support. At the same time, the nurse can provide health promotion \& psychosocial services include assessment, health education, counseling \& appropriate referral ${ }^{[6-14]}$.

\subsection{Significance of the Study}

Most of the pregnant women experienced minor discomforts in their normal pregnancies. These minor discomforts may result in physiologic, anatomic, endocrinal/hormonal changes ${ }^{[15-16]}$. The hormonal changes during pregnancy may play havoc with women's emotions, making them more vulnerable to anxiety. The gestational period is thus a potential stressor and relatively a high-risk period for women with pre-existing many psychological health problems which arise during or soon after pregnancy. Many views of mundane life provoke anxiety, various situations and conditions can increase the frequency and severity of the anxiety and pregnancy can often amplify this anxiety. Some women are most worried about whether their babies are healthy. Anxiety during pregnancy may be associated with a variety of adverse consequences in term of obstetrics complications and pregnancy outcomes ${ }^{[17-19]}$. Although minor discomforts aren't life-threatening, nevertheless their presence detracts from the mother feeling of comfort and well-being as well as their negligence may lead to serious problems. In many instances, they can be avoided by preventive and self-care measures ones can do.

\subsection{Operational Definitions}

Minor discomfort was defined by Beischer and Mackay as slightly ailments of pregnancy which lead to lack of comfort and annoying rather than disabling the client ${ }^{[20]}$.

Anxiety: anxiety describes a state of the mind and experience of unpleasant effect which develops depending on environmental stimulants that are perceived by the individuals as being dangerous or threatening when confronted with specific situations, demands or a particular object or event ${ }^{[21-24]}$.

\section{Aim of the Study}

The current study aimed to evaluate the effect of an educational on women's anxiety and knowledge about pregnancy minor discomforts and their self-intervention among primigravida mothers attending to Beni-Suef general hospital antenatal clinic. This aim will be obtained through the following:

Assess the pregnant women's knowledge regarding pregnancy minor discomforts and their self-intervention.

Assess the level of anxiety among primigravida pregnant women with Zung's-self-rating-anxiety-scale.

Implement a tailored teaching program (TTP) for pregnant women with pregnancy minor discomforts to improve their knowledge and self-management as well and decrease their anxiety.

Evaluate the effectiveness of a tailored teaching program (TTP) on reducing the anxiety and gain in knowledge regarding minor discomforts and their self-intervention among primigravida women.

Find out the associations between women's knowledge scores and anxiety level and general characteristics among primigravida throughout the period of program implementation (pre/post/follow-up). 


\section{Research Hypothesis}

The researchers hypothesized that:

After implementing the program, women's knowledge regarding minor discomforts and their self-intervention will be improved among primigravida women. The mean post-test and retained-test knowledge's scores of pregnant women will be significantly higher than their mean pre-test knowledge's score at a significant level 0.05 .

The women's anxiety levels will be decreased or relieved after program implementation. The mean post-test and retained-test of anxiety scores of pregnant women will be significantly less than their mean pre-test anxiety scores at a significant level 0.05 .

There will be a significant statistical association between knowledge score and anxiety scores, the higher the knowledge, the lower the anxiety levels, at a significant level 0.05 .

There will be a statistically significant association between knowledge scores, socio-demographic variables at the level of significance $(\mathrm{P} \leq 0.05)$.

\section{Methods and Subjects}

\subsection{Research Design}

A quasi-experimental design was used.

\subsection{Setting}

The data collection for this study took place in the outpatient clinics affiliated to antenatal care units at Beni- Suef Public Hospital in Beni-Suef city, Egypt.

\subsection{Participants}

A purposive sample of 50 primigravida pregnant women, suffering from minor disorders of pregnancy, was taken from the clients who attended the antenatal clinic in the previously mentioned hospital in Beni-Suef city from April, $1^{\text {st }} 2019$ to June, $30^{\text {th }} 2019$ were approached. All participants should fulfill the following inclusion criteria; (1) Primigravida pregnant women with minor discomforts, (2) Have a single fetus, (3) Pregnancy free from any complications such as medical disorders, (4) Have not experienced any psychological disorder or treatment, (5) Welling to participate.

\subsection{Assessment Tools}

Three tools were used for collecting the relevant data.

Tool (I): A structured knowledge questionnaire:

After a comprehensive reviewing of the academic literature, the researchers designed and developed an interviewing questionnaire sheet to assess women's knowledge through evaluating knowledge about minor discomforts and their self-management for pregnant women attending governmental hospitals in Beni-Suef city. It consists of two sections which describes socio-demographic and family characteristics of respondents containing six items (age, educational level, occupation, residence, family income, and type of family).

Tool (II): Zung's-Self-Rating-Anxiety-Scale: ${ }^{[25]}$

Standardized-Zung's-Self-Rating-Anxiety-Scale is used to assess the anxiety level. This scale includes 20 questions with a total maximum score of 80 . Some questions ask for the information positively (15 positive statements) and others negatively ( 5 negative statements). But in all cases, the severity of the symptoms is scored from one to four. (1) = none or little of the time answer, (2) = some of the time answer, (3) = a large part of the time answer, (4) = the most or all of the time answer. The total raw score was converted to an anxiety index (100- point scale). Thereby, Anxiety Index $=$ (the raw score $/ 80$ total points) $* 100$ OR anxiety index raw $=$ raw score $* 1.25$. Total scoring of the pregnant women's anxiety index is $(100)$. So $<45$ points considered "Normal anxiety", 45 points to 59 point considered "Minimal to Moderate anxiety", 60 points to 74 points considered "Marked to Severe anxiety", and $>74$ points to 100 points considered "Extreme anxiety".

Tool (III): Pre-test/post-test/retained-test knowledge assessment sheet:

This was designed to assess the women's knowledge regarding minor discomforts and their self-management. The scoring keys for Knowledge questionnaire of 25 items were with a maximum score of 50. Incorrect answer or don't know get (0), correct answer but wasn't complete get (1) while complete and correct answer get (2).

This sheet was distributed to all participants 3 times; (1) pre-test to assess women's knowledge before implementation of the program. (2) Post-test to assess woman's knowledge immediately after the implementation 
of the program. (3) Retained or follow-up test; three months after implementation of the program. Knowledge questionnaire of 50 items was designed by the researchers, on three aspects with a total maximum score of 100 as the following: woman who has $\geq 75 \%$ correct answer ( 75 points to 100 points) will get "Good" score, woman who has $\geq 50 \%$ to $<75 \%$ correct answer (50 points to 74 points) will get "Average" score, woman who has $<50 \%$ correct answer ( 0 point to 49 points) will get "Poor" score,

\subsection{Methods and Phases of Data Collection}

\subsubsection{Validity \& Reliability of the Tools}

The tools were revised for their content validity by 3 experts in the field. They were senior staff members with experience in obstetrics \& gynecological, maternity and mental health nursing. The recommended modifications were made.

The tool is reliable as reliability was assessed by Cronbach's alpha coefficient test. The result of the test was 0.86 .

\subsubsection{Administrative Approval}

Official letter that described the objectives and the aim of the study was directed from the Faculty of Nursing, Beni-Suef University to the directorate of the previously mentioned hospital in Beni-Suef city to obtain the permission to collect the research subject from the hospital under his directorate.

\subsubsection{Ethical Considerations}

Verbal consent took from each participant before including her in the study. Every woman informed that her participation is totally voluntary; she can withdraw from the study whenever she decided. After taking consent from each participant, the researcher introduced, clarified and explained the purpose and all the objectives of the study. Total confidentiality to obtain information, as well as respect for privacy, was ensured.

\subsubsection{Pilot Study}

A pilot study was done on five pregnant women. The results of the pilot study revealed the relevance, clarity, and applicability of the study tools. Women involved in the pilot were excluded from the study to avoid contamination of the study sample. The necessarily required modifications were done.

\subsubsection{Phases of Fieldwork}

The study enrolled 50 pregnant women with minor discomforts. Each participant took, approximately, 30-45 minutes to complete the interview questionnaire. Four phases were adopted to fulfill the purpose of the study as following mentioned: (A) assessment phase, (B) Planning phase, (C) implementing phase, and (D) evaluation phase. The four phases of data collection took 3 months (from April 1, 2019, to June 30, 2019).

Assessment phase:

The pre-test included; assessment of knowledge and the anxiety level among the pregnant women with minor discomforts through a structured-knowledge-questionnaire and standardized Zung's-self-rating-anxiety-scale. The obtained data during this phase were constituted the baseline for further comparison to evaluate the effect of the implemented educational program. Each woman was interviewed to collect socio-demographic data and general characteristics to assess their baseline knowledge about minor discomforts and self-management.

Planning phase:

After comprehensive reviewing of the relevant academic literature, from journals, magazines, books, bulletins and the electronic media, the researchers developed a tailored educational program that was administered at the end of the pre- test. It contained the definition, causes and self-management.

Implementation Phase:

The design of the program was based on the pre-existing women's knowledge regarding minor discomforts. The program consisted of four sessions, each session lasting 15-30 minutes. 
Table 1. Overview of the elements in educational program about minor discomforts of pregnancy

\begin{tabular}{|c|c|c|c|}
\hline Session & Elements & Objectives & Method \\
\hline $\begin{array}{l}\text { Session no. } \\
1\end{array}$ & Opening Ceremony & $\begin{array}{l}\text { 1. Welcome } \\
\text { 2. Presentation program objectives. } \\
\text { 3. Enumerate the participants' expectations. } \\
\text { 4. Distribution of pre-test. }\end{array}$ & Discussion. \\
\hline $\begin{array}{l}\text { Session no. } \\
2\end{array}$ & $\begin{array}{l}\text { knowledge regarding } \\
\text { minor discomforts of } \\
\text { pregnancy }\end{array}$ & $\begin{array}{l}\text { 1. Define minor discomforts. } \\
\text { 2. Enumerate the common minor disorders } \\
\text { of the pregnancy } \\
\text { 3. Identify causes of minor discomforts. } \\
\text { 4. List signs and symptoms. }\end{array}$ & $\begin{array}{l}\text { Brain storming } \\
\text { Power point. } \\
\text { Video. }\end{array}$ \\
\hline $\begin{array}{l}\text { Session no. } \\
3\end{array}$ & $\begin{array}{l}\text { knowledge regarding } \\
\text { self-management } \\
\text { minor discomforts of } \\
\text { pregnancy }\end{array}$ & $\begin{array}{l}\text { 1. Identify methods self-management to } \\
\text { overcome of minor discomforts of } \\
\text { pregnancy. }\end{array}$ & $\begin{array}{ll}\text { lecture } & \text { with } \\
\text { discussion } & \\
\text { Power point } & \\
\text { Questions } & \text { and } \\
\text { answers } & \end{array}$ \\
\hline $\begin{array}{l}\text { Session no. } \\
4\end{array}$ & Closing & $\begin{array}{l}\text { 1. Participant's evaluation for the program. } \\
\text { 2. Distribution of Post-test. }\end{array}$ & $\begin{array}{l}\text { Distributing } \\
\text { educational } \\
\text { booklet } \\
\text { Summary } \\
\text { Conclusion. } \\
\begin{array}{l}\text { Thanks to all } \\
\text { participants. }\end{array}\end{array}$ \\
\hline
\end{tabular}

Evaluation phase:

During this phase, the program was evaluated by using the same previously formatted data collection tools. The immediate evaluation after the program was conducted as a post-test. Another evaluation subsequent follow-up phase (retained-test) was scheduled; three months later.

\subsubsection{Data Analysis}

Recorded data were analyzed using the statistical package for social sciences, version 20.0 (SPSS Inc., Chicago, Illinois, USA). Quantitative data were presented as mean and standard deviation (Mean $\pm \mathrm{SD}$ ). Qualitative data were presented as frequency and percentage $(\mathrm{N} \& \%)$. The following tests were done:

Chi-square $\left(\mathrm{x}^{2}\right)$ test of significance was used in order to compare proportions between qualitative parameters.

Pearson's correlation coefficient (г) test was used to assess the degree of association between two sets of variables The confidence interval was set to $95.0 \%$ and the margin of error accepted was set to $5.0 \%$. So, the P-value was considered significant as the following:

$$
\begin{aligned}
& \text { P-value }<0.05 \text { was considered significant. } \\
& \text { P-value }<0.001 \text { was considered as highly significant. } \\
& \text { P-value }>0.05 \text { was considered insignificant. }
\end{aligned}
$$

\section{Results}

The data in Table 2 presents that the mean age of the study sample was $(25.80 \pm 7.48)$. More than half of them $(52.0 \%)$ were in the middle age (21-30) years old, $28.0 \%$ of them had primary education, $58.0 \%$ and $56.0 \%$ had no work and rural residence, respectively. The bulky percent of them $(78.0 \%)$ live in extended family; the majority $(90.0 \%)$ of them had unsatisfied family income.

Table (3) shows the level of anxiety of the participant women according to all items (20 items) of the Zung's-Self-Rating-Anxiety-Scale. Highly significant differences were found pre and posttest for all measured items (P-value $<0.001)$. Moreover, more than half of the items (30 items) scored either highly significant differences or significant differences between post and retained test (P-value $<0.001$ ).

Figure (1) shows the effectiveness of the implemented program on women's anxiety. It is clear that, marked, severe, and extreme anxiety regressed and dissolved immediately after implemented program and continued to the follow-up period (post/retained test), $(0.0 \% \& 0.0 \%$, respectively). A statistically significant difference between women's anxiety as regarding pre/post/retained test according to total-self-rating-anxiety-scale was observed (P-value $<0.001$ ).

Table (4) presents the knowledge of the participating pregnant women regarding minor discomforts (50 items) throughout the 3 phases of the study implementation (pre/post/retained). Highly significant differences were 
found pre and posttest for all measured items (P-value $<0.001$ ). Moreover, more than half of the items ( 34 of 50 items, $60.0 \%$ ) scored either significant differences between post and retained test (P-value $<0.05$ ).

Figure 2 portrays the total knowledge score among the studied pregnant women with minor discomforts throughout the 3 phases of the study implementation (pre/post/retained). It is observed that women's total knowledge improved and progressed immediately after implemented program and continued to the follow-up period (post/retained test). Poor score changed from $82.0 \%$ in pre-implementation to $0.0 \%$ in post-implementation. Additionally, good score changed from $0.0 \%$ in pre-implementation to $80.0 \%$ in post-implementation. There was a statistically significant difference between the total-knowledge-score regarding minor disorders of pregnancy of the pre/post-test regarding total knowledge (P-value $<0.001$ ).

Table 5 illustrates the relationship between pregnant women's level of anxiety according to Self-Rating-Anxiety-Scale and their socio-demographic data throughout pre/post/retained tests. A statistical significant relationship between the pregnant women level of anxiety and their residences and educational level $(\mathrm{P}<0.05)$ in pre-test is declared. However, in post-test the significant relationships are observed between women level of anxiety and their age, education, and family income $(\mathrm{P}<0.05)$. Moreover, in retained-test, the significances are observed as the same in the pre-test (age, and education), $(\mathrm{P}<0.05)$.

Table 6 illustrates the relationship between pregnant women's knowledge regarding minor disorders of pregnancy and their socio-demographic data throughout pre/post/retained tests. A statistical significant relationship between the pregnant women's knowledge regarding minor disorders of pregnancy and their residences, occupation status $(\mathrm{P}<0.001)$, and educational level $(\mathrm{P}<0.05)$ in pre-test is observed. However, in post-test, the significant relationships are found between women's knowledge and their residence, and family income $(\mathrm{P}<0.05)$, and educational level $(\mathrm{P}<0.001)$. Moreover, in retained-test, the significances are observed between women's knowledge and their residence, education, and occupation $(\mathrm{P}<0.05)$.

Table 7 shows statistical significant relations between the primigravida pregnant women level of knowledge and their self-rating anxiety scale $(\mathrm{P}<0.001)$.

Table 8 presents the correlation between pregnant women total-self-rating-anxiety-scale and total knowledge score. Pearson correlation coefficient test $(\Gamma)$ revealed that, the high knowledge score result in low anxiety level score. A statistically significant correlation between the pregnant women total knowledge score and their total self-rating anxiety scale was found $(\mathrm{P}<0.001)$.

Table 2. Distribution of pregnant women according to their socio-demographic data $(\mathrm{N}=50)$

\begin{tabular}{lcc}
\hline Socio-Demographic Characteristics & No. & $\%$ \\
\hline Age (years) & 10 & 20 \\
\hline a. $\leq 20$ - years & 26 & 52 \\
\hline b. $21-30$ years & 14 & 28 \\
\hline c. $>30$ years & $25.80 \pm 7.48$ \\
\hline Mean \pm SD & 14 & 28 \\
\hline Educational status & 19 & 38 \\
\hline a. Primary & 15 & 30 \\
\hline b. Secondary & 2 & 4 \\
\hline c. Higher secondary & & \\
\hline d. Graduation \& above & 29 & 58 \\
\hline Occupational status & 13 & 26 \\
\hline a. House wife & 8 & 16 \\
\hline b. Daily wages & & \\
\hline c. Government work & 22 & 44 \\
\hline Residence: & 28 & 56 \\
\hline a. Urban & & \\
\hline b. Rural & 45 & 90 \\
\hline Monthly income of the family & 5 & 10 \\
\hline a. Unsatisfied (not enough) & 0 & 0 \\
\hline b. Just enough (enough for living only) & & \\
\hline c. Satisfy (enough \& can save from it ) & 11 & 22 \\
\hline Type of family & 39 & 78 \\
\hline a. Nuclear & & \\
\hline b. Extended & & \\
\hline & & \\
\hline
\end{tabular}


Table 3. Descriptive statistics for pre, post and retained women's anxiety according self-rating-anxiety-scale $(n=50)$

\begin{tabular}{lllllllll}
\multirow{2}{*}{ Self-rating anxiety scale } & \multicolumn{2}{c}{ Pre } & \multicolumn{2}{c}{ Post } & \multicolumn{2}{c}{ Retained } & \multicolumn{2}{c}{ P-value } \\
\cline { 2 - 8 } & No. & $\%$ & No. & $\%$ & No. & $\%$ & Pre \& Post & $\begin{array}{c}\text { Post \& } \\
\text { Retained }\end{array}$ \\
\hline
\end{tabular}

\begin{tabular}{|c|c|c|c|c|c|c|c|c|c|}
\hline \multirow{3}{*}{$\begin{array}{l}\text { 1. I feel more } \\
\text { nervous/anxious } \\
\text { the }\end{array}$} & A. None or Little of the time & 5 & 10 & 22 & 44 & 24 & 48 & \multirow{3}{*}{$<0.001 * *$} & \multirow{3}{*}{$0.042 *$} \\
\hline & B. Some of the time & 8 & 16 & 27 & 54 & 18 & 36 & & \\
\hline & C. A large part of the time & 19 & 38 & 0 & 0 & 6 & 12 & & \\
\hline
\end{tabular}

than usual.

\begin{tabular}{lllllll}
\hline D. All or Most of the time & 18 & 36 & 1 & 2 & 2 & 4
\end{tabular}

\begin{tabular}{llllllll} 
& A. None or Little of the time & 5 & 10 & 24 & 48 & 18 & 36 \\
\cline { 2 - 9 } & B. Some of the time & 9 & 18 & 25 & 50 & 19 & 38
\end{tabular}

$\begin{array}{lllllllll}n & \text { no reason at all. } & \text { C. A large part of the time } & 23 & 46 & 0 & 0 & 12 & 24\end{array}<0.001 * * 003 *$

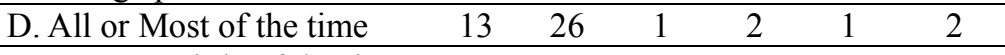

\section{I get upset} easily or feel panicky.

\begin{tabular}{lcccccc} 
A. None or Little of the time & 2 & 4 & 27 & 54 & 15 & 30 \\
\hline B. Some of the time & 15 & 30 & 21 & 42 & 28 & 56 \\
\hline
\end{tabular}

\begin{tabular}{llllllll} 
C. A large part of the time & 18 & 36 & 2 & 4 & 7 & 14 \\
\hline
\end{tabular}

$\begin{array}{lllllll}\text { D. All or Most of the time } & 15 & 30 & 0 & 0 & 0 & 0\end{array}$

4. I feel like I am

$\begin{array}{lllllll}\text { A. None or Little of the time } & 16 & 32 & 41 & 82 & 28 & 56\end{array}$

falling apart and going to pieces.

B. Some of the time

C. A large part of the time

$21 \quad 42$

D. All or Most of the time

5. I feel that A. None or Little of the time

$9 \quad 18$

$\begin{array}{ccccc}42 & 8 & 16 & 18 & 36 \\ 18 & 1 & 2 & 4 & 8\end{array}$

$<0.001 * * \quad 0.018^{*}$

everything is all right and nothing bad will happen.

6. My arms and legs shake and tremble.

\begin{tabular}{lcccccc} 
A. None or Little of the time & 26 & 52 & 22 & 44 & 24 & 48 \\
\hline B. Some of the time & 14 & 28 & 9 & 18 & 23 & 46
\end{tabular}

$\begin{array}{cccccc}4 & 8 & 0 & 0 & 0 & 0 \\ 26 & 52 & 22 & 44 & 24 & 48\end{array}$

\begin{tabular}{|c|c|}
\hline 0.223 & $0.003^{*}$ \\
\hline$<0.001 * *$ & $0.019^{*}$ \\
\hline
\end{tabular}

7. I am bothered by headaches, neck and back pains.

$\begin{array}{llllllll}\text { D. All or Most of the time } & 6 & 12 & 13 & 26 & 1 & 2\end{array}$

$\begin{array}{llllllll}\text { A. None or Little of the time } & 2 & 4 & 22 & 44 & 32 & 64\end{array}$

\begin{tabular}{lcccccc}
\hline B. Some of the time & 19 & 38 & 26 & 52 & 13 & 26
\end{tabular}

$\begin{array}{lllllll}\text { C. A large part of the time } & 19 & 38 & 1 & 2 & 5 & 10\end{array}$

$\begin{array}{llllllll}\text { D. All or Most of the time } & 10 & 20 & 1 & 2 & 0 & 0\end{array}$

$\begin{array}{lcccccc}\text { D. All or Most of the time } & 10 & 20 & 1 & 2 & 0 & 0 \\ \text { A. None or Little of the time } & 1 & 2 & 20 & 40 & 33 & 66\end{array}$

\begin{tabular}{lcccccc} 
A. None or Little of the time & 1 & 2 & 20 & 40 & 33 & 66 \\
\hline B. Some of the time & 9 & 18 & 28 & 56 & 15 & 30 \\
\hline C. A large part of the time & 21 & 42 & 2 & 4 & 2 & 4 \\
\hline
\end{tabular}

\begin{tabular}{llllllll}
\hline D. All or Most of the time & 19 & 38 & 0 & 0 & 0 & 0
\end{tabular}

$\begin{array}{llllllll}\text { A. None or Little of the time } & 2 & 4 & 25 & 50 & 25 & 50\end{array}$

8. I feel weak and

get tired easily.

Some of the time

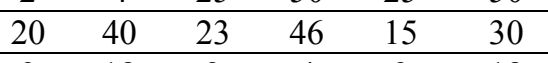

$\begin{array}{lcccccc}\text { C. A large part of the time } & 9 & 18 & 2 & 4 & 9 & 18\end{array}$

$<0.001^{* *}$

0.068 $\begin{array}{lllllll}\text { D. All or Most of the time } & 19 & 38 & 0 & 0 & 1 & 2\end{array}$

\begin{tabular}{llllllll} 
& A. None or Little of the time & 30 & 60 & 13 & 26 & 20 & 40 \\
\cline { 2 - 10 } 9. I feel calm and & B. Some of the time & 11 & 22 & 7 & 14 & 19 & 38
\end{tabular}

can sit still easily.

C. A large part of the time

$\begin{array}{cccccc}11 & 22 & 7 & 14 & 19 & 38 \\ 2 & 4 & 10 & 20 & 10 & 20\end{array}$

$<0.001 * *<0.001 * *$

$\begin{array}{lllllll}\text { D. All or Most of the time } & 7 & 14 & 20 & 40 & 1 & 2\end{array}$

10. I can feel my

A. None or Little of the time

heart beating fast.

B. Some of the time

$5 \quad 10$

Some of the time $14 \quad 28$

C. A large part of the time

$24 \quad 48$

D. All or Most of the time

$\begin{array}{cc}24 & 48 \\ 7 & 14\end{array}$

11. I have

fainting spells or

feel like it.

A. None or Little of the time

$\begin{array}{llllll}7 & 14 & 31 & 62 & 35 & 70\end{array}$

$\begin{array}{lllllll}\text { B. Some of the time } & 20 & 40 & 19 & 38 & 13 & 26\end{array}$

\begin{tabular}{|lccccccc} 
C. A large part of the time & 21 & 42 & 0 & 0 & 2 & 4 \\
\hline D. All or Most of the time & 2 & 4 & 0 & 0 & 0 & 0
\end{tabular}

$<0.001 * * \quad 0.011^{*}$

$\begin{array}{lllllll}\text { A. None or Little of the time } & 13 & 26 & 35 & 70 & 29 & 58\end{array}$

12. I can breathe

in and out easily.

B. Some of the time

$\begin{array}{lll}17 & 34 & 14\end{array}$

$\begin{array}{llll}35 & 70 & 29 & 58 \\ 14 & 28 & 19 & 38\end{array}$

C. A large part of the time

$15 \quad 30$

D. All or Most of the time

13. I get feelings

of numbness and

A. None or Little of the time

$5 \quad 10$

10

1

$\begin{array}{ccc}3 & 6 & 29 \\ 17 & 34 & 20\end{array}$

29

2

12

$<0.001 * *$

B. Some of the time

$\begin{array}{ccc}0 & 1 & 2 \\ 58 & 31 & 62 \\ 40 & 15 & 30\end{array}$

$<0.001 * *$ 


\begin{tabular}{|c|c|c|c|c|c|c|c|c|c|}
\hline \multirow{2}{*}{\multicolumn{2}{|c|}{ Self-rating anxiety scale }} & \multicolumn{2}{|c|}{ Pre } & \multicolumn{2}{|c|}{ Post } & \multicolumn{2}{|c|}{ Retained } & \multicolumn{2}{|c|}{ P-value } \\
\hline & & \multirow{2}{*}{$\begin{array}{c}\text { No. } \\
18 \\
\end{array}$} & \multirow{2}{*}{$\begin{array}{l}\% \\
36 \\
\end{array}$} & \multirow{2}{*}{$\begin{array}{c}\text { No. } \\
0\end{array}$} & \multirow{2}{*}{$\begin{array}{l}\% \\
0 \\
\end{array}$} & \multirow{2}{*}{$\begin{array}{c}\text { No. } \\
4 \\
\end{array}$} & \multirow{2}{*}{$\begin{array}{c}\% \\
8 \\
\end{array}$} & \multirow[t]{3}{*}{ Pre \& Post } & \multirow[t]{3}{*}{$\begin{array}{c}\text { Post \& } \\
\text { Retained }\end{array}$} \\
\hline tingling in my & C. A large part of the time & & & & & & & & \\
\hline fingers and toes. & D. All or Most of the time & 12 & 24 & 1 & 2 & 0 & 0 & & \\
\hline \multirow{4}{*}{$\begin{array}{l}\text { 14. I am bothered } \\
\text { by stomach aches } \\
\text { and indigestion. }\end{array}$} & A. None or Little of the time & 0 & 0 & 22 & 44 & 22 & 44 & \multirow{4}{*}{$<0.001 * *$} & \multirow{4}{*}{$0.007^{*}$} \\
\hline & B. Some of the time & 6 & 12 & 28 & 56 & 18 & 36 & & \\
\hline & C. A large part of the time & 19 & 38 & 0 & 0 & 9 & 18 & & \\
\hline & D. All or Most of the time & 25 & 50 & 0 & 0 & 1 & 2 & & \\
\hline \multirow{4}{*}{$\begin{array}{l}\text { 15. I have to } \\
\text { empty my } \\
\text { bladder often. }\end{array}$} & A. None or Little of the time & 0 & 0 & 22 & 44 & 27 & 54 & \multirow{4}{*}{$<0.001 * *$} & \multirow{4}{*}{0.314} \\
\hline & B. Some of the time & 5 & 10 & 27 & 54 & 20 & 40 & & \\
\hline & C. A large part of the time & 13 & 26 & 1 & 2 & 1 & 2 & & \\
\hline & D. All or Most of the time & 32 & 64 & 0 & 0 & 2 & 4 & & \\
\hline \multirow{4}{*}{$\begin{array}{l}\text { 16. My hands are } \\
\text { usually warm and } \\
\text { dry. }\end{array}$} & A. None or Little of the time & 2 & 4 & 23 & 46 & 33 & 66 & \multirow{4}{*}{$<0.001 * *$} & \multirow{4}{*}{$0.022 *$} \\
\hline & B. Some of the time & 12 & 24 & 25 & 50 & 12 & 24 & & \\
\hline & C. A large part of the time & 22 & 44 & 2 & 4 & 5 & 10 & & \\
\hline & D. All or Most of the time & 14 & 28 & 0 & 0 & 0 & 0 & & \\
\hline \multirow{4}{*}{$\begin{array}{l}\text { 17. My face gets } \\
\text { hot and blushes. }\end{array}$} & A. None or Little of the time & 1 & 2 & 32 & 64 & 27 & 54 & \multirow{4}{*}{$<0.001 * *$} & \multirow{4}{*}{0.401} \\
\hline & B. Some of the time & 22 & 44 & 18 & 36 & 22 & 44 & & \\
\hline & C. A large part of the time & 18 & 36 & 0 & 0 & 0 & 0 & & \\
\hline & D. All or Most of the time & 9 & 18 & 0 & 0 & 1 & 2 & & \\
\hline \multirow{4}{*}{$\begin{array}{l}\text { 18. I fall asleep } \\
\text { easily and get a } \\
\text { good night's rest. }\end{array}$} & A. None or Little of the time & 28 & 56 & 14 & 28 & 14 & 28 & \multirow{4}{*}{$<0.001^{* *}$} & \multirow{4}{*}{$<0.001 * *$} \\
\hline & B. Some of the time & 14 & 28 & 6 & 12 & 28 & 56 & & \\
\hline & C. A large part of the time & 4 & 8 & 11 & 22 & 8 & 16 & & \\
\hline & D. All or Most of the time & 4 & 8 & 19 & 38 & 0 & 0 & & \\
\hline & A. None or Little of the time & 33 & 66 & 39 & 78 & 28 & 56 & & \\
\hline 19. I have & B. Some of the time & 9 & 18 & 10 & 20 & 18 & 36 & & 0,05 \\
\hline nightmares. & C. A large part of the time & 3 & 6 & 1 & 2 & 4 & 8 & 001 & 0.052 \\
\hline & D. All or Most of the time & 5 & 10 & 0 & 0 & 0 & 0 & & \\
\hline & A. None or Little of the time & 5 & 10 & 22 & 44 & 23 & 46 & & \\
\hline 20. I am bothered & B. Some of the time & 8 & 16 & 27 & 54 & 17 & 34 & & \\
\hline by dizzy spells. & C. A large part of the time & 19 & 38 & 0 & 0 & 7 & 14 & $.001^{* 6}$ & $0.016^{*}$ \\
\hline & D. All or Most of the time & 18 & 36 & 1 & 2 & 3 & 6 & & \\
\hline
\end{tabular}

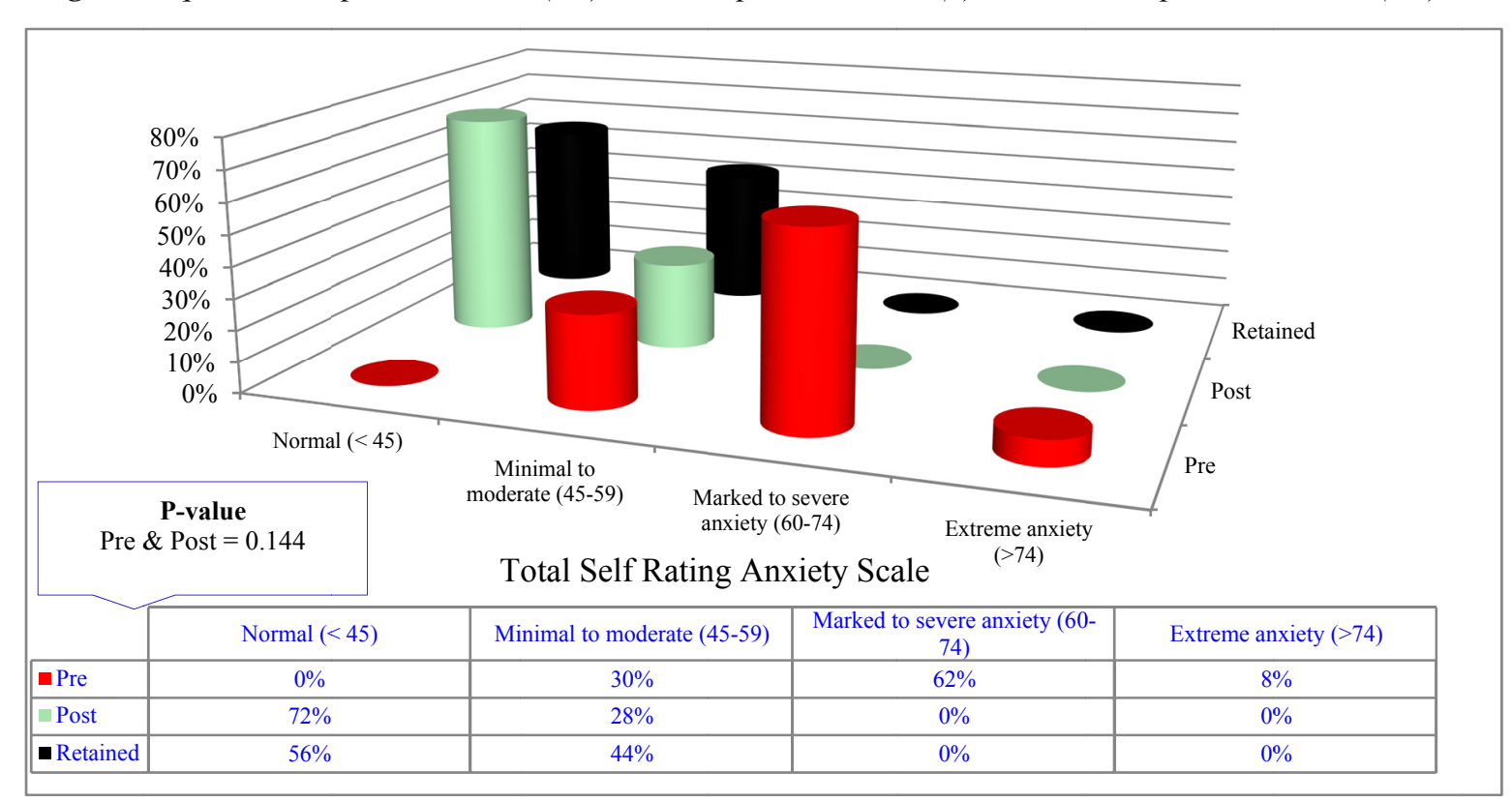

Figure 1. Distribution total self-rating anxiety scale among the studied pregnant women with minor discomforts 
Table 4. Descriptive statistics for pre, post and retained knowledge regarding minor disorders of pregnancy

\begin{tabular}{|c|c|c|c|c|c|c|c|c|c|}
\hline \multirow{2}{*}{\multicolumn{2}{|c|}{ Knowledge Regarding Minor Disorders of Pregnancy }} & \multicolumn{2}{|c|}{ Pre } & \multicolumn{2}{|c|}{ Post } & \multicolumn{2}{|c|}{ Retained } & \multicolumn{2}{|c|}{ P-value } \\
\hline & & No. & $\%$ & No. & $\%$ & No. & $\%$ & Pre/Post & Post/Retained \\
\hline \multirow{2}{*}{$\begin{array}{l}\text { 1. Causes of morning sickness (Nausea \& } \\
\text { vomiting) during pregnancy }\end{array}$} & Incorrect answer & 36 & 72 & 10 & 20 & 5 & 10 & \multirow{2}{*}{$\begin{array}{c}< \\
0.001 * * \\
\end{array}$} & \multirow{2}{*}{0.263} \\
\hline & Correct answer & 14 & 28 & 40 & 80 & 45 & 90 & & \\
\hline \multirow{2}{*}{$\begin{array}{l}\text { 2. Self-Management of morning sickness } \\
\text { (Nausea \& vomiting) during pregnancy }\end{array}$} & Incorrect answer & 24 & 48 & 9 & 18 & 5 & 10 & \multirow{2}{*}{$\begin{array}{c}< \\
0.001 * * \\
\end{array}$} & \multirow{2}{*}{0.387} \\
\hline & Correct answer & 26 & 52 & 41 & 82 & 45 & 90 & & \\
\hline \multirow{2}{*}{$\begin{array}{l}\text { 3. Causes of Ptyalism (excessive salivation) } \\
\text { during pregnancy }\end{array}$} & Incorrect answer & 44 & 88 & 12 & 24 & 5 & 10 & \multirow{2}{*}{$\begin{array}{c}< \\
0.001 * *\end{array}$} & \multirow{2}{*}{0.111} \\
\hline & Correct answer & 6 & 12 & 38 & 76 & 45 & 90 & & \\
\hline \multirow{2}{*}{$\begin{array}{l}\text { 4. Self-Management of Ptyalism (excessive } \\
\text { salivation) during pregnancy }\end{array}$} & Incorrect answer & 40 & 80 & 11 & 22 & 7 & 14 & \multirow{2}{*}{$\begin{array}{c}< \\
0.001 * * \\
\end{array}$} & \multirow{2}{*}{0.434} \\
\hline & Correct answer & 10 & 20 & 39 & 78 & 43 & 86 & & \\
\hline \multirow{2}{*}{ 5. Causes of pica during pregnancy } & Incorrect answer & 46 & 92 & 15 & 30 & 5 & 10 & $<$ & \\
\hline & Correct answer & 4 & 8 & 35 & 70 & 45 & 90 & $0.001 * *$ & \\
\hline & Incorrect answer & 30 & 60 & 13 & 26 & 4 & 8 & $<$ & 003 \\
\hline 0. & Correct answer & 20 & 40 & 37 & 74 & 46 & 92 & $0.001 * *$ & 0.053 \\
\hline & Incorrect answer & 14 & 28 & 0 & 0 & 0 & 0 & $<$ & \\
\hline & Correct answer & 36 & 72 & 50 & 100 & 50 & 100 & $0.001 * *$ & 1.000 \\
\hline & ct answer & 31 & 62 & 5 & 10 & 3 & 6 & $<$ & \\
\hline & Correct answer & 19 & 38 & 45 & 90 & 47 & 94 & $0.001 * *$ & \\
\hline & Incorrect answer & 43 & 86 & 13 & 26 & 2 & 4 & $<$ & 000 \\
\hline 9. & Correct answer & 7 & 14 & 37 & 74 & 48 & 96 & $0.001 * *$ & 0.005 \\
\hline 10. Self-Manageme & Incorrect answer & 41 & 82 & 26 & 52 & 2 & 4 & $<$ & \\
\hline & Correct answer & 9 & 18 & 24 & 48 & 48 & 96 & $0.001 * *$ & \\
\hline 11 & Incorrect answer & 26 & 52 & 9 & 18 & 2 & 4 & $<$ & \\
\hline & answer & 24 & 48 & 41 & 82 & 48 & 96 & $0.001 * *$ & \\
\hline 12. Self-Management of flatulence during & Incorrect answer & 42 & 84 & 12 & 24 & 1 & 2 & $<$ & 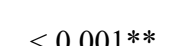 \\
\hline & Correct answer & 8 & 16 & 38 & 76 & 49 & 98 & $0.001 * *$ & $<0.001$ \\
\hline & Incorrect answer & 36 & 72 & 12 & 24 & 2 & 4 & $<$ & \\
\hline & Correct answer & 14 & 28 & 38 & 76 & 48 & 96 & $0.001 * *$ & \\
\hline 14. Self-Management of constipation during & Incorrect answer & 31 & 62 & 12 & 24 & 1 & 2 & $<$ & \\
\hline pregnancy & Correct answer & 19 & 38 & 38 & 76 & 49 & 98 & $0.001 * *$ & \\
\hline 15. Causes of fecal impaction and melena & Incorrect answer & 45 & 90 & 15 & 30 & 1 & 2 & $<$ & $<0001 *$ \\
\hline during pre & Correct answer & 5 & 10 & 35 & 70 & 49 & 98 & $0.001 * *$ & \\
\hline 16. Self-Management of fecal impaction and & Incorrect answer & 34 & 68 & 9 & 18 & 4 & 8 & $<$ & \\
\hline & Correct answer & 16 & 32 & 41 & 82 & 46 & 92 & $0.001 * *$ & \\
\hline 17 & Incorrect answer & 38 & 76 & 10 & 20 & 5 & 10 & $<$ & \\
\hline & Correct answer & 12 & 24 & 40 & 80 & 45 & 90 & $0.001 * *$ & \\
\hline 18. Self-Management of hemorrhoids during & Incorrect answer & 48 & 96 & 37 & 74 & 34 & 68 & $<$ & 0659 \\
\hline & Correct answer & 2 & 4 & 13 & 26 & 16 & 32 & $0.001 * *$ & 0.659 \\
\hline 19. Causes of round ligament pain during & Incorrect answer & 48 & 96 & 27 & 54 & 8 & 16 & $<$ & \\
\hline pregnancy & Correct answer & 2 & 4 & 23 & 46 & 42 & 84 & $0.001 * *$ & 0.002 \\
\hline 20. Self-Management of round ligament pain & Incorrect answer & 46 & 92 & 15 & 30 & 8 & 16 & $<$ & \\
\hline & Correct answer & 4 & 8 & 35 & 70 & 42 & 84 & $0.001 * *$ & \\
\hline 21 Causes of leucorrhea durino & Incorrect answer & 45 & 90 & 17 & 34 & 6 & 12 & $<$ & $0.018 *$ \\
\hline & Correct answer & 5 & 10 & 33 & 66 & 44 & 88 & $0.001 * *$ & \\
\hline 22. Self-Management of leucorrhea during & Incorrect answer & 43 & 86 & 15 & 30 & 5 & 10 & $<$ & \\
\hline & Correct answer & 7 & 14 & 35 & 70 & 45 & 90 & $0.001 * *$ & 0.02 \\
\hline & Incorrect answer & 39 & 78 & 10 & 20 & 3 & 6 & $<$ & \\
\hline 25. Causes of vuival itcning auring pregnancy & Correct answer & 11 & 22 & 40 & 80 & 47 & 94 & $0.001 * *$ & 0.0 \\
\hline 24. Self-Management of vulval itching during & Incorrect answer & 35 & 70 & 10 & 20 & 3 & 6 & $<$ & \\
\hline & Correct answer & 15 & 30 & 40 & 80 & 47 & 94 & $0.001 * *$ & \\
\hline 25. Causes of increase frequency of & Incorrect answer & 49 & 98 & 26 & 52 & 5 & 10 & $<$ & \\
\hline micturition during pregnancy & Correct answer & 1 & 2 & 24 & 48 & 45 & 90 & $0.001 * *$ & \\
\hline
\end{tabular}




\begin{tabular}{|c|c|c|c|c|c|c|c|c|c|}
\hline \multirow{2}{*}{\multicolumn{2}{|c|}{ Knowledge Regarding Minor Disorders of Pregnancy }} & \multicolumn{2}{|c|}{ Pre } & \multicolumn{2}{|c|}{ Post } & \multicolumn{2}{|c|}{ Retained } & \multicolumn{2}{|c|}{ P-value } \\
\hline & & No. & $\%$ & No. & $\%$ & No. & $\%$ & Pre/Post & Post/Retained \\
\hline \multirow{2}{*}{$\begin{array}{l}\text { 26. Self-Management of increase frequency of } \\
\text { micturition during pregnancy }\end{array}$} & Incorrect answer & 45 & 90 & 18 & 36 & 2 & 4 & $<$ & \multirow{2}{*}{$<0.001 * *$} \\
\hline & Correct answer & 5 & 10 & 32 & 64 & 48 & 96 & $0.001 * *$ & \\
\hline \multirow{2}{*}{ 27. Causes of dyspnea during pregnancy } & Incorrect answer & 39 & 78 & 7 & 14 & 2 & 4 & $<$ & \multirow{2}{*}{0.162} \\
\hline & Correct answer & 11 & 22 & 43 & 86 & 48 & 96 & $0.001 * *$ & \\
\hline \multirow{2}{*}{$\begin{array}{l}\text { 28. Self-Management of dyspnea during } \\
\text { pregnancy }\end{array}$} & Incorrect answer & 36 & 72 & 11 & 22 & 2 & 4 & $<$ & \multirow{2}{*}{$0.017 *$} \\
\hline & Correct answer & 14 & 28 & 39 & 78 & 48 & 96 & $0.001 * *$ & \\
\hline \multirow{2}{*}{ 29. Causes of fainting during pregnancy } & Incorrect answer & 12 & 24 & 0 & 0 & 0 & 0 & $<$ & \multirow{2}{*}{1.000} \\
\hline & Correct answer & 38 & 76 & 50 & 100 & 50 & 100 & $0.001 * *$ & \\
\hline \multirow{2}{*}{$\begin{array}{l}\text { 30. Self-Management of fainting during } \\
\text { pregnancy }\end{array}$} & Incorrect answer & 13 & 26 & 2 & 4 & 1 & 2 & $<$ & \multirow{2}{*}{0.624} \\
\hline & Correct answer & 37 & 74 & 48 & 96 & 49 & 98 & $0.001 * *$ & \\
\hline \multirow{2}{*}{ 31. Causes of low back ache during pregnancy } & Incorrect answer & 39 & 78 & 11 & 22 & 1 & 2 & $<$ & \multirow{2}{*}{$0.006^{*}$} \\
\hline & Correct answer & 11 & 22 & 39 & 78 & 49 & 98 & $0.001 * *$ & \\
\hline \multirow{2}{*}{$\begin{array}{l}\text { 32. Self-Management of low back ache during } \\
\text { pregnancy }\end{array}$} & Incorrect answer & 37 & 74 & 13 & 26 & 1 & 2 & $<$ & \\
\hline & Correct answer & 13 & 26 & 37 & 74 & 49 & 98 & $0.001 * *$ & $0.002^{*}$ \\
\hline $32+3$ & Incorrect answer & 46 & 92 & 19 & 38 & 1 & 2 & $<$ & $<$ \\
\hline 33. Caus & Correct answer & 4 & 8 & 31 & 62 & 49 & 98 & $0.001 * *$ & $<0.001$ \\
\hline 34. Self-Management of leg cramps during & Incorrect answer & 45 & 90 & 14 & 28 & 8 & 16 & $<$ & ( 227 \\
\hline pregnancy & Correct answer & 5 & 10 & 36 & 72 & 42 & 84 & $0.001 * *$ & 0.221 \\
\hline & Incorrect answer & 45 & 90 & 13 & 26 & 0 & 0 & $<$ & \\
\hline 35 & Correct answer & 5 & 10 & 37 & 74 & 50 & 100 & $0.001 * *$ & \\
\hline 36. Self-Management of varicose vain during & Incorrect answer & 36 & 72 & 10 & 20 & 2 & 4 & $<$ & $0031 *$ \\
\hline nreonancy & Correct answer & 14 & 28 & 40 & 80 & 48 & 96 & $0.001 * *$ & $0.031^{*}$ \\
\hline & Incorrect answer & 34 & 68 & 9 & 18 & 1 & 2 & $<$ & \\
\hline 37. Causes of edema durıng pregnancy & Correct answer & 16 & 32 & 41 & 82 & 49 & 98 & $0.001 * *$ & \\
\hline 38. Self-Management of edema during & Incorrect answer & 42 & 84 & 21 & 42 & 10 & 20 & $<$ & \\
\hline pregnancy & Correct answer & 8 & 16 & 29 & 58 & 40 & 80 & $0.001 * *$ & 0.0 \\
\hline 39. Causes of breast heaviness and tenderness & Incorrect answer & 43 & 86 & 14 & 28 & 5 & 10 & $<$ & $0.041 *$ \\
\hline during pregnancy & Correct answer & 7 & 14 & 36 & 72 & 45 & 90 & $0.001 * *$ & $0.041^{*}$ \\
\hline 40. Self-Management of breast heaviness and & Incorrect answer & 38 & 76 & 13 & 26 & 0 & 0 & $<$ & \\
\hline tenderness during pregnancy & Correct answer & 12 & 24 & 37 & 74 & 50 & 100 & $0.001 * *$ & 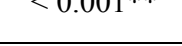 \\
\hline 41. Causes of Carpal tunnel syndrome (CTS) & Incorrect answer & 41 & 82 & 14 & 28 & 2 & 4 & $<$ & \\
\hline during pregnancy & Correct answer & 9 & 18 & 36 & 72 & 48 & 96 & $0.001 * *$ & \\
\hline 42. Self-Management of Carpal tunnel & Incorrect answer & 42 & 84 & 16 & 32 & 5 & 10 & $<$ & \\
\hline & Correct answer & 8 & 16 & 34 & 68 & 45 & 90 & $0.001 * *$ & \\
\hline & Incorrect answer & 46 & 92 & 19 & 38 & 1 & 2 & $<$ & \\
\hline 4. & Correct answer & 4 & 8 & 31 & 62 & 49 & 98 & $0.001 * *$ & \\
\hline 44. Self-Management of headache during & Incorrect answer & 40 & 80 & 13 & 26 & 0 & 0 & $<$ & \\
\hline pregnancy & Correct answer & 10 & 20 & 37 & 74 & 50 & 100 & $0.001 * *$ & \\
\hline 45. Causes of sleep disturbance (insomnia) & Incorrect answer & 43 & 86 & 11 & 22 & 2 & 4 & $<$ & \\
\hline during pregnancy & Correct answer & 7 & 14 & 39 & 78 & 48 & 96 & $0.001 * *$ & \\
\hline 46. Self-Management of sleep disturbance & Incorrect answer & 48 & 96 & 10 & 20 & 2 & 4 & $<$ & \\
\hline & Correct answer & 2 & 4 & 40 & 80 & 48 & 96 & $0.001 * *$ & 0310 \\
\hline & Incorrect answer & 45 & 90 & 7 & 14 & 0 & 0 & $<$ & \\
\hline & Correct answer & 5 & 10 & 43 & 86 & 50 & 100 & $0.001 * *$ & \\
\hline 48. Self-Management of fatigue during & Incorrect answer & 46 & 92 & 27 & 54 & 3 & 6 & $<$ & \\
\hline & Correct answer & 4 & 8 & 23 & 46 & 47 & 94 & $0.001 * *$ & \\
\hline 49. Causes of nasal stuffiness during & Incorrect answer & 45 & 90 & 10 & 20 & 0 & 0 & $<$ & \\
\hline pregnancy & Correct answer & 5 & 10 & 40 & 80 & 50 & 100 & $0.001 * *$ & $0.003^{\circ}$ \\
\hline 50. Self-Management of nasal stuffiness & Incorrect answer & 45 & 90 & 15 & 30 & 10 & 20 & $<$ & \\
\hline during pregnancy & Correct answer & 5 & 10 & 35 & 70 & 40 & 80 & $0.001 * *$ & 60 \\
\hline
\end{tabular}




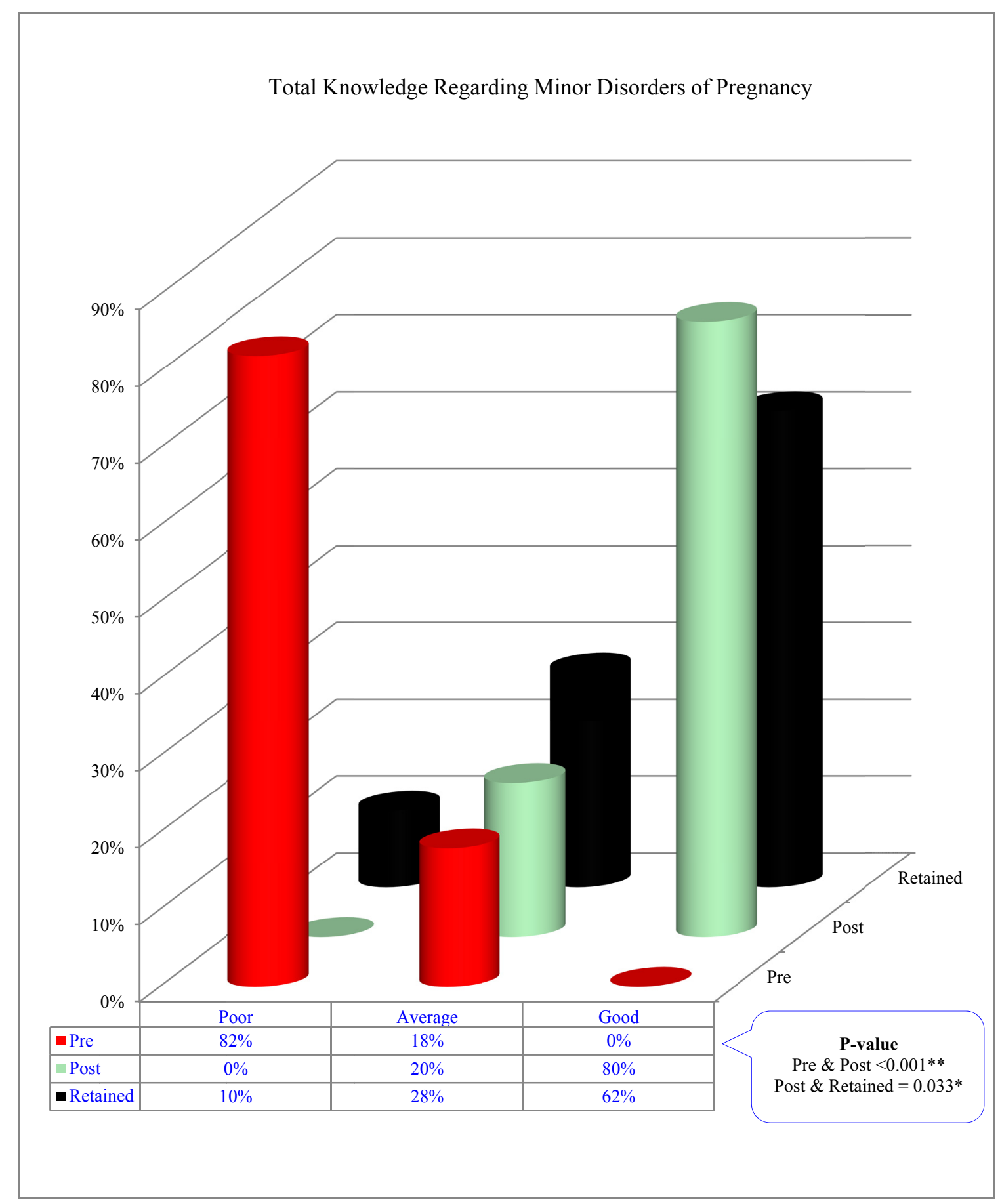

Figure 2. Distribution total knowledge score among the studied pregnant women with minor discomforts 
Table 5. Relation between pregnant women's level of anxiety and their socio-demographic data $(n=50)$

\begin{tabular}{|c|c|c|c|c|c|c|c|c|c|c|c|c|c|c|}
\hline \multirow{4}{*}{$\begin{array}{l}\text { Socio-Demographic } \\
\text { data }\end{array}$} & \multicolumn{14}{|c|}{ level of anxiety according to Self-Rating-Anxiety-Scale } \\
\hline & \multicolumn{6}{|c|}{ Pre } & \multicolumn{4}{|c|}{ Post } & \multicolumn{4}{|c|}{ Retained } \\
\hline & \multicolumn{2}{|c|}{$\begin{array}{c}\text { Minimal to } \\
\text { moderate }(n=15)\end{array}$} & \multicolumn{2}{|c|}{$\begin{array}{l}\text { Marked to severe } \\
\qquad(\mathrm{n}=31)\end{array}$} & \multicolumn{2}{|c|}{ Extreme $(\mathrm{n}=4)$} & \multicolumn{2}{|c|}{ Normal $(\mathrm{n}=36)$} & \multicolumn{2}{|c|}{$\begin{array}{c}\text { Minimal to } \\
\text { moderate ( }(n=14)\end{array}$} & \multicolumn{2}{|c|}{ Normal $(n=28)$} & \multicolumn{2}{|c|}{$\begin{array}{c}\text { Minimal to } \\
\text { moderate } \\
(\mathrm{n}=22)\end{array}$} \\
\hline & No. & $\%$ & No. & $\%$ & No. & $\%$ & No. & $\%$ & No. & $\%$ & No. & $\%$ & No. & $\%$ \\
\hline \multicolumn{15}{|l|}{ 1. Age (years) } \\
\hline a. $\leq 20-$ years & 0 & $0.0 \%$ & 10 & $32.3 \%$ & 0 & $0.0 \%$ & 9 & $25.0 \%$ & 1 & $7.1 \%$ & 8 & $28.6 \%$ & 2 & $9.1 \%$ \\
\hline b. 21-30 years & 8 & $53.3 \%$ & 15 & $48.4 \%$ & 3 & $75.0 \%$ & 15 & $41.7 \%$ & 11 & $78.6 \%$ & 9 & $32.1 \%$ & 17 & $77.3 \%$ \\
\hline c. Above 30 years & 7 & $46.7 \%$ & 6 & $19.4 \%$ & 1 & $25.0 \%$ & 12 & $33.3 \%$ & 2 & $14.3 \%$ & 11 & $39.3 \%$ & 3 & $13.6 \%$ \\
\hline Chi-square test & \multicolumn{6}{|c|}{3.326} & \multicolumn{4}{|c|}{9.553} & \multicolumn{4}{|c|}{10.058} \\
\hline$p$-value & \multicolumn{6}{|c|}{0.053} & \multicolumn{4}{|c|}{$0.032 *$} & \multicolumn{4}{|c|}{$0.007 *$} \\
\hline \multicolumn{15}{|l|}{ 2. Education } \\
\hline a. Primary & 1 & $6.7 \%$ & 10 & $32.3 \%$ & 3 & $75.0 \%$ & 12 & $33.3 \%$ & 2 & $14.3 \%$ & 8 & $28.6 \%$ & 6 & $27.3 \%$ \\
\hline b. Secondary & 4 & $26.7 \%$ & 14 & $45.2 \%$ & 1 & $25.0 \%$ & 16 & $44.4 \%$ & 3 & $21.4 \%$ & 15 & $53.6 \%$ & 4 & $18.2 \%$ \\
\hline c. Higher secondary & 8 & $53.3 \%$ & 7 & $22.6 \%$ & 0 & $0.0 \%$ & 6 & $16.7 \%$ & 9 & $64.3 \%$ & 3 & $10.7 \%$ & 12 & $54.5 \%$ \\
\hline $\begin{array}{l}\text { d.Graduation \& } \\
\text { above }\end{array}$ & 2 & $13.3 \%$ & 0 & $0.0 \%$ & 0 & $0.0 \%$ & 2 & $5.6 \%$ & 0 & $0.0 \%$ & 2 & $7.1 \%$ & 0 & $0.0 \%$ \\
\hline Chi-square test & \multicolumn{6}{|c|}{16.056} & \multicolumn{4}{|c|}{11.108} & & 13.52 & & \\
\hline p-value & & & & $.013^{*}$ & & & & & & & & 0.004 & & \\
\hline 3. Occupation & & & & & & & & & & & & & & \\
\hline a. House wife & 9 & $60.0 \%$ & 17 & $54.8 \%$ & 3 & $75.0 \%$ & 23 & $63.9 \%$ & 6 & $42.9 \%$ & 17 & $60.7 \%$ & 12 & $54.5 \%$ \\
\hline b. Daily wages & 3 & $20.0 \%$ & 10 & $32.3 \%$ & 0 & $0.0 \%$ & 7 & $19.4 \%$ & 6 & $42.9 \%$ & 6 & $21.4 \%$ & 7 & $31.8 \%$ \\
\hline c. Government & 3 & $20.0 \%$ & 4 & $12.9 \%$ & 1 & $25.0 \%$ & 6 & $16.7 \%$ & 2 & $14.3 \%$ & 5 & $17.9 \%$ & 3 & $13.6 \%$ \\
\hline Chi-square test & & & & 2.516 & & & & & & & & 0.72 & & \\
\hline p-value & & & & 0.642 & & & & & & & & 0.69 & & \\
\hline 4. Residence: & & & & & & & & & & & & & & \\
\hline a. Urban & 2 & $13.3 \%$ & 17 & $54.8 \%$ & 3 & $75.0 \%$ & 15 & $41.7 \%$ & 7 & $50.0 \%$ & 10 & $35.7 \%$ & 12 & $54.5 \%$ \\
\hline b. Rural & 13 & $86.7 \%$ & 14 & $41.9 \%$ & 1 & $25.0 \%$ & 21 & $55.6 \%$ & 7 & $50.0 \%$ & 18 & $64.3 \%$ & 10 & $40.9 \%$ \\
\hline Chi-square test & & & & 9.943 & & & & & & & & 3.51 & & \\
\hline p-value & & & & $.041^{*}$ & & & & & & & & 0.17 & & \\
\hline 5. Monthly income & & & & & & & & & & & & & & \\
\hline a. Not enough & 15 & $100.0 \%$ & 26 & $83.9 \%$ & 4 & $100.0 \%$ & 34 & $94.4 \%$ & 11 & $78.6 \%$ & 26 & $92.9 \%$ & 19 & $86.4 \%$ \\
\hline $\begin{array}{l}\text { b. Enough for living } \\
\text { only }\end{array}$ & 0 & $0.0 \%$ & 5 & $16.1 \%$ & 0 & $0.0 \%$ & 2 & $5.6 \%$ & 3 & $21.4 \%$ & 2 & $7.1 \%$ & 3 & $13.6 \%$ \\
\hline Chi-square test & & & & 3.405 & & & & & & & & 0.57 & & \\
\hline$p$-value & & & & 0.182 & & & & & & & & 0.47 & & \\
\hline 6. Type of family & & & & & & & & & & & & & & \\
\hline a. Nuclear & 5 & $33.3 \%$ & 6 & $19.4 \%$ & 0 & $0.0 \%$ & 10 & $27.8 \%$ & 1 & $7.1 \%$ & 7 & $25.0 \%$ & 4 & $18.2 \%$ \\
\hline b. Extended & 10 & $66.7 \%$ & 25 & $80.6 \%$ & 4 & $100.0 \%$ & 26 & $72.2 \%$ & 13 & $92.9 \%$ & 21 & $75.0 \%$ & 18 & $81.8 \%$ \\
\hline Chi-square test & & & & 2.377 & & & & & & & & 0.33 & & \\
\hline p-value & & & & 0.305 & & & & & & & & 0.56 & & \\
\hline$p$-value $>0$ & VS) & & $*$ & alue & 50 & & & $p-1$ & $e<$ & $\left(H_{\curlywedge}\right.$ & & & & \\
\hline
\end{tabular}


Table 6. Relation between pregnant women's knowledge regarding minor disorders of pregnancy and their socio-demographic data $(\mathrm{n}=50)$

\begin{tabular}{|c|c|c|c|c|c|c|c|c|c|c|c|c|c|c|}
\hline \multirow{4}{*}{$\begin{array}{l}\text { Socio-Demographic } \\
\text { data }\end{array}$} & \multicolumn{14}{|c|}{ Women's Knowledge Regarding Minor Disorders of Pregnancy } \\
\hline & \multicolumn{4}{|c|}{ Pre } & \multicolumn{4}{|c|}{ Post } & \multicolumn{6}{|c|}{ Retained } \\
\hline & \multicolumn{2}{|c|}{ Poor $(n=41)$} & \multicolumn{2}{|c|}{ Average $(\mathrm{n}=9)$} & \multicolumn{2}{|c|}{ Average $(n=10)$} & \multirow{2}{*}{$\begin{array}{l}\text { Good } \\
\text { No. }\end{array}$} & \multirow{2}{*}{$\frac{(n=40)}{\%}$} & \multicolumn{2}{|c|}{ Poor $(\mathbf{n}=5)$} & \multicolumn{2}{|c|}{ Average $(n=14)$} & \multicolumn{2}{|c|}{ Good $(n=31)$} \\
\hline & No. & $\%$ & No. & $\%$ & No. & $\%$ & & & No. & $\%$ & No. & $\%$ & No. & $\%$ \\
\hline
\end{tabular}

\section{Age (years)}

\begin{tabular}{|c|c|c|c|c|c|c|c|c|c|c|c|c|c|c|}
\hline a. $\leq 20$ - years & 10 & $24.4 \%$ & 0 & $0.0 \%$ & 0 & $0.0 \%$ & 10 & $25.0 \%$ & 0 & $0.0 \%$ & 3 & $21.4 \%$ & 7 & $22.6 \%$ \\
\hline b. $21-30$ years & 18 & $43.9 \%$ & 8 & $88.9 \%$ & 7 & $70.0 \%$ & 19 & $47.5 \%$ & 4 & $80.0 \%$ & 9 & $64.3 \%$ & 13 & $41.9 \%$ \\
\hline c. Above 30 years & 13 & $31.7 \%$ & 1 & $11.1 \%$ & 3 & $30.0 \%$ & 11 & $27.5 \%$ & 1 & $20.0 \%$ & 2 & $14.3 \%$ & 11 & $35.5 \%$ \\
\hline Chi-square test & \multicolumn{4}{|c|}{6.185} & \multicolumn{4}{|c|}{3.297} & \multicolumn{6}{|c|}{4.556} \\
\hline p-value & \multicolumn{4}{|c|}{$0.045^{*}$} & \multicolumn{4}{|c|}{0.192} & \multicolumn{6}{|c|}{0.336} \\
\hline
\end{tabular}

\section{Educational status}

\begin{tabular}{|c|c|c|c|c|c|c|c|c|c|c|c|c|c|c|}
\hline a. Primary & 14 & $34.1 \%$ & 0 & $0.0 \%$ & 10 & $100.0 \%$ & 4 & $10.0 \%$ & 5 & $100.0 \%$ & 5 & $35.7 \%$ & 4 & $12.9 \%$ \\
\hline b. Secondary & 18 & $43.9 \%$ & 1 & $11.1 \%$ & 0 & $0.0 \%$ & 19 & $47.5 \%$ & 0 & $0.0 \%$ & 4 & $28.6 \%$ & 15 & $48.4 \%$ \\
\hline c. Higher secondary & 9 & $22.0 \%$ & 6 & $66.7 \%$ & 0 & $0.0 \%$ & 15 & $37.5 \%$ & 0 & $0.0 \%$ & 5 & $35.7 \%$ & 10 & $32.3 \%$ \\
\hline d. Graduation \& above & 0 & $0.0 \%$ & 2 & $22.2 \%$ & 0 & $0.0 \%$ & 2 & $5.0 \%$ & 0 & $0.0 \%$ & 0 & $0.0 \%$ & 2 & $6.5 \%$ \\
\hline Chi-square test & \multicolumn{4}{|c|}{19.191} & \multicolumn{4}{|c|}{32.143} & \multicolumn{6}{|c|}{18.117} \\
\hline$p$-value & \multicolumn{4}{|c|}{$<0.001 * *$} & \multicolumn{4}{|c|}{$<0.001 * *$} & \multicolumn{6}{|c|}{$0.006^{*}$} \\
\hline \multicolumn{15}{|l|}{ 3. Occupational status } \\
\hline a. House wife & 28 & $68.3 \%$ & 1 & $11.1 \%$ & 7 & $70.0 \%$ & 22 & $55.0 \%$ & 3 & $60.0 \%$ & 12 & $85.7 \%$ & 14 & $45.2 \%$ \\
\hline b. Daily wages & 5 & $12.2 \%$ & 8 & $88.9 \%$ & 0 & $0.0 \%$ & 13 & $32.5 \%$ & 0 & $0.0 \%$ & 1 & $7.1 \%$ & 12 & $38.7 \%$ \\
\hline c. Government & 8 & $19.5 \%$ & 0 & $0.0 \%$ & 3 & $30.0 \%$ & 5 & $12.5 \%$ & 2 & $40.0 \%$ & 1 & $7.1 \%$ & 5 & $16.1 \%$ \\
\hline Chi-square test & \multicolumn{4}{|c|}{22.612} & \multicolumn{4}{|c|}{5.092} & \multicolumn{6}{|c|}{10.366} \\
\hline p-value & \multicolumn{4}{|c|}{$<0.001^{* *}$} & \multicolumn{4}{|c|}{$0.048 *$} & \multicolumn{6}{|c|}{$0.035^{*}$} \\
\hline
\end{tabular}

\section{Residence:}

\begin{tabular}{|c|c|c|c|c|c|c|c|c|c|c|c|c|c|c|}
\hline a. Urban & 18 & $43.9 \%$ & 4 & $44.4 \%$ & 7 & $70.0 \%$ & 15 & $37.5 \%$ & 3 & $60.0 \%$ & 8 & $57.1 \%$ & 11 & $35.5 \%$ \\
\hline b. Rural & 23 & $53.7 \%$ & 5 & $55.6 \%$ & 3 & $20.0 \%$ & 25 & $62.5 \%$ & 2 & $20.0 \%$ & 6 & $42.9 \%$ & 20 & $64.5 \%$ \\
\hline Chi-square test & \multicolumn{4}{|c|}{0.225} & \multicolumn{4}{|c|}{8.596} & \multicolumn{6}{|c|}{12.379} \\
\hline p-value & \multicolumn{4}{|c|}{0.894} & \multicolumn{4}{|c|}{$0.014^{*}$} & \multicolumn{6}{|c|}{$0.015^{*}$} \\
\hline
\end{tabular}

\section{Monthly income}

\begin{tabular}{lccccccccccccccc}
\hline a. Not enough & 38 & $92.7 \%$ & 7 & $77.8 \%$ & 9 & $90.0 \%$ & 36 & $90.0 \%$ & 5 & $100.0 \%$ & 12 & $85.7 \%$ & 28 & $90.3 \%$ \\
\hline b. Enough for living & 3 & $7.3 \%$ & 2 & $22.2 \%$ & 1 & $10.0 \%$ & 4 & $10.0 \%$ & 0 & $0.0 \%$ & 2 & $14.3 \%$ & 3 & $9.7 \%$
\end{tabular}
only

\begin{tabular}{|c|c|c|c|c|c|c|c|c|c|c|c|c|c|c|}
\hline Chi-square test & \multicolumn{4}{|c|}{1.822} & \multicolumn{4}{|c|}{0.000} & \multicolumn{6}{|c|}{0.845} \\
\hline p-value & \multicolumn{4}{|c|}{0.177} & \multicolumn{4}{|c|}{1.000} & \multicolumn{6}{|c|}{0.655} \\
\hline \multicolumn{15}{|l|}{ 6. Type of family } \\
\hline a. Nuclear & 10 & $24.4 \%$ & 1 & $11.1 \%$ & 2 & $20.0 \%$ & 9 & $22.5 \%$ & 2 & $40.0 \%$ & 4 & $28.6 \%$ & 5 & $16.1 \%$ \\
\hline b. Extended & 31 & $75.6 \%$ & 8 & $88.9 \%$ & 8 & $80.0 \%$ & 31 & $77.5 \%$ & 3 & $60.0 \%$ & 10 & $71.4 \%$ & 26 & $83.9 \%$ \\
\hline Chi-square test & \multicolumn{4}{|c|}{0.758} & \multicolumn{4}{|c|}{0.029} & \multicolumn{6}{|c|}{1.919} \\
\hline p-value & \multicolumn{4}{|c|}{0.384} & \multicolumn{4}{|c|}{0.864} & \multicolumn{6}{|c|}{0.383} \\
\hline
\end{tabular}


Table 7. Relation between pregnant women self-rating anxiety scale and level of knowledge $(n=50)$

\begin{tabular}{|c|c|c|c|c|c|c|c|c|c|c|c|c|c|c|}
\hline \multirow{4}{*}{$\begin{array}{l}\text { Knowledge } \\
\text { Regarding } \\
\text { Minor } \\
\text { Disorders of } \\
\text { Pregnancy }\end{array}$} & \multicolumn{14}{|c|}{ Self-rating anxiety scale } \\
\hline & \multicolumn{6}{|c|}{ Pre } & \multicolumn{4}{|c|}{ Post } & \multicolumn{4}{|c|}{ Retained } \\
\hline & \multicolumn{2}{|c|}{$\begin{array}{l}\text { Minimal to } \\
\text { moderate } \\
(n=15)\end{array}$} & \multicolumn{2}{|c|}{$\begin{array}{l}\text { Marked to severe } \\
\text { anxiety }(n=31)\end{array}$} & \multicolumn{2}{|c|}{$\begin{array}{l}\text { Extreme } \\
\text { anxiety } \\
(n=4)\end{array}$} & \multicolumn{2}{|c|}{ Normal $(n=36)$} & \multicolumn{2}{|c|}{$\begin{array}{c}\text { Minimal to } \\
\text { moderate }(n=14)\end{array}$} & \multicolumn{2}{|c|}{$\begin{array}{l}\text { Normal } \\
(n=28)\end{array}$} & \multicolumn{2}{|c|}{$\begin{array}{l}\text { Minimal to } \\
\text { moderate (n } \\
\quad=22)\end{array}$} \\
\hline & No. & $\%$ & No. & $\%$ & No. & $\%$ & No. & $\%$ & No. & $\%$ & No. & $\%$ & No. & $\%$ \\
\hline Poor & 11 & 73.3 & 28 & 90.3 & 2 & 50.0 & 0 & 0.0 & 0 & 0.0 & 0 & 0.0 & 5 & 22.7 \\
\hline Average & 4 & 26.7 & 3 & 9.7 & 2 & 50.0 & 1 & 2.8 & 9 & 64.3 & 2 & 7.1 & 12 & 54.5 \\
\hline Good & 0 & 0.0 & 0 & 0.0 & 0 & 0.0 & 35 & 97.2 & 5 & 35.7 & 26 & 92.9 & 5 & 22.7 \\
\hline Chi-square test & \multicolumn{6}{|c|}{2.150} & \multicolumn{4}{|c|}{20.145} & \multicolumn{4}{|c|}{0.334} \\
\hline p-value & \multicolumn{6}{|c|}{0.482} & \multicolumn{4}{|c|}{$<0.001 * *$} & \multicolumn{4}{|c|}{$<0.001 * *$} \\
\hline
\end{tabular}

**p-value $<0.001$ (HS)

Table 8. Correlation between pregnant women total-self-rating-anxiety-scale and total knowledge score $(\mathrm{n}=50)$

\begin{tabular}{ccccc}
\hline & \multicolumn{4}{c}{ Total Knowledge Regarding Minor Disorders of Pregnancy } \\
\cline { 2 - 5 } & & Pre & Post & Retained \\
\hline \multirow{2}{*}{ Total-Self-Rating-Anxiety-Scale } & $\mathrm{r}$ & 0.196 & 0.752 & 0.639 \\
\cline { 2 - 5 } & $\mathrm{p}$-value & 0.472 & $<0.001^{* *}$ & $<0.001^{* *}$ \\
\hline
\end{tabular}

p-value $>0.05(N S)$

$* *$-value $<0.001(H S)$

\section{Discussion}

An extensive amount of studies has shown the adverse outcomes of maternal psychological state. Given the potentially high prevalence of anxiety during pregnancy; Trait anxiety arises in response to a perceived threat. Anxiety is a normal response to threat or danger and part of the usual human experience, but it can become a mental health problem if the response is exaggerated and interferes with daily life ${ }^{[26-28]}$.

During the period of pregnancy, woman will undergo a lot of physical, psychological and hormonal changes but these changes are normal. These changes cause minor discomforts during pregnancy. They are called minor because they aren't life-threatening. A lot of these discomforts may calm-down in this pregnancy progress, but it causes inconvenience and stress to most of the pregnant women. Every system of the body is affected by pregnancy. Providing information about physiology, prevention, and self-care of pregnancy discomforts can assist in relieving certain anxiety and fears related to the maternity care is healthy pregnancy with physically safe and emotionally satisfying outcome for mother, infant, and family ${ }^{[29]}$.

The pregnant women need the knowledge to cope with the experience of pregnancy particularly in primigravida at Upper Egypt where there were different cultural, social and behavioral conditions. Additionally, where it is evidenced that for those who have poor knowledge regarding minor disorders during pregnancy it is to be estimated that most of the discomforts can be controlled through proper education. Consistent health supervision and surveillance are of importance in achieving this outcome ${ }^{[30-32]}$. Hence, the present study was aimed to evaluate the impact of a tailored educational program on primigravida anxiety and knowledge regarding minor discomforts in Upper Egypt. This aim was significantly achieved because there are statistically significantly improved post educational session and follow up knowledge level and self-rating-anxiety-scale regarding minor discomforts compared to pre-education.

Regarding socio-demographic characteristics, the result of the present study revealed that mean age of the participants was $25.80 \pm 7.48$, more than one-third (38.0\%) of them had secondary education, and more than half were housewives $(58.8 \%)$ and $(56.0 \%)$ were from rural residence, respectively. Finally, the findings of the present study discovered that the majority of primigravida included in their extended family with unsatisfied monthly income. These results reflect their sensitivity to the customs and traditions of the place where they live. This nearly agrees with the findings of study conducted at antenatal clinic at Benha university hospital-Egypt to 
evaluate the effect of self-care practice guideline on relieving minor discomfort (ailments) among new pregnant woman ${ }^{[33]}$, and also similar to the study done at Maternal Child Health services Menofia Government, Egypt compare between primigravida and multigravida regarding women's self-care practices for management of selected minor discomfort ${ }^{[34]}$

Concerning the primigravida self-rating-anxiety-scale of pregnancy minor discomforts, the current study exposed that there was a statistically significant difference of the studied sample regarding total self-rating-anxiety-scale after the educational program and at follow up time compared to their self-rating-anxiety-scale before it (P-value $<0.001)$. In the pretest no one of the study sample hadn't anxiety; that anxiety level ranged from minimal level to extreme one. While, in the post and retained test, the data analysis present that most women get free of anxiety and a fewer percentage reported minimal to moderate anxiety. Moreover, no one reported marked, severe, or extreme anxiety. Accordingly, the study hypothesis is accepted. The present study findings indicated that providing the primigravida with educational sessions was significantly relieved the majority of the self-rating-anxiety-scale of pregnancy discomforts post-intervention. Similarly, the study concluded that the structured teaching program was effective in terms of reduction in anxiety and gain knowledge regarding the minor disorders among primigravida ${ }^{[35]}$.

As regards to primigravida knowledge about minor disorders of pregnancy, results of the present study proved that there was statistically significant difference of the studied women's total knowledge regarding minor disorders of pregnancy after educational program and at follow-up time compared to their knowledge before it regarding correct management of pregnancy minor disorders. These findings are in accordance with the study done at obstetrics and gynecology clinic of women's health hospital, Assiut-Egypt that the study group who received the educational guidelines were more knowledgeable and aware of the concept of the antenatal aspects as; diet during pregnancy, food that could prevent constipation, preparation for breastfeeding, weight increment during pregnancy, taking multi-vitamins and iron supplements and time to approach health care provider during pregnancy, care of minor problems, and care of their newborn ${ }^{[35]}$.

According to the findings of the current study, it was revealed that pregnant women exhibited relationship between level of anxiety and their socio-demographic variables, statistically significant between some variables such as age and educational status and monthly income of the family, while no significant between other variables as occupational status, type of family and place of residence and anxiety level. Moreover, there were also statistically significant relations between the primigravida women's post-intervention level of knowledge and their socio-demographic data variables presented in the educational level, occupation and residence place. These findings of the study done at the Egyptian Public Hospital in Beni-Suef demonstrated that primigravida anxiety correlates well with demographic variables include age and educational levels. Primigravida women who are younger and who attain lower education level may find more challenges in adjusting new role and a new set of expectations from themselves and others, and thus they are more likely to manifest anxiety symptoms in early pregnancy. Additionally, those women don't participate in prenatal care due to lack of money, lack of transportation or language barriers ${ }^{[36]}$.

Concerning to the participants women' condition of pre-information, the greater part of participants had poor knowledge with a marked increased severity level of self-rating-anxiety-scale regarding minor discomfort of pregnancy. This appears because the participants' decreased of emotional support, lack of knowledge, different socio-cultural background as well as educational-level. Post-intervention educational session the majority of the participants' women had minimal to moderate level of self-rating-anxiety-scale with an average level of knowledge. This may be due to the utilization of simple and clear language in the educational session, the appropriate teaching method and audiovisual aids and this confirmed by statistically significant correlation between the primigravida women total knowledge score and their total self-rating-anxiety-scale after educational session and at follow up time compared to their before it $(\mathrm{p}<0.001)$.

Briefly, the tailored educational program has a positive effect on women's knowledge and anxiety associated with pregnancy. It improved their knowledge and regress their anxiety. Pearson correlation coefficient test revealed, that the anxiety level of the subset of expectant mothers whose high mean knowledge score was significantly lower anxiety level than the other of the group of primigravida pregnant women whose low mean knowledge score; Pre-program $(\Gamma=0.196, \mathrm{p}=0.472)$, Post-program $(\Gamma=0.752, \mathrm{p}<0.001)$ and retained $(\mathrm{r}=$ $0.639, \mathrm{p}<0.001)$. This was in agreement with Ahmed (2015) who conduct a quasi-experimental study on the effectiveness of self-instructional-module on knowledge regarding antenatal care for safe motherhood among primigravida and found that a significant progress and improvement in primigravida women's knowledge after the administration of self-instructional-module on safe motherhood ${ }^{[37]}$. In similar line with Latha et al (2016) who conduct Pre-experimental one group pretest-posttest design on sixty antenatal mothers to examine 
Effectiveness of IEC (Information, Education \& Communication) package on knowledge regarding minor ailments of pregnancy and its management among antenatal mothers at NMCH, Nellore, A.P. The results showed that the IEC package was effective in increasing the knowledge level of women regarding minor ailments of pregnancy ${ }^{[38]}$. These findings are also supported by Ahmed (2015) who highly statistically significant improvement knowledge ${ }^{[37]}$. Finally, findings of the current study hold up the study hypothesis that educational program for primigravida women will improve and get better their self-rating-anxiety-scale and enhance their average level of knowledge about minor discomfort of pregnancy.

\section{Limitations of the Study}

Taking extra time for completing the sessions due to noise, working hours and the interruption done by the participants' relatives

\section{Conclusion}

The majority of the participant's women had poor knowledge with a marked increased severity level of self-rating-anxiety-scale regarding minor discomfort of pregnancy. Designing and implementing an educational program about the studied subject indicated a significant effect in a remarkable rising of the primigravida level of knowledge with minimizing their level of anxiety. These findings reflected the willingness of the primigravida women to achieve more information about the issue and their preferences to self-manage the minor disorders instead of taking medications for the sake of the healthy child.

\section{Recommendations}

Based on the findings of this study, the following recommendations are suggested:

1. Provision of the educational guidelines of the minor disorders to the antenatal clinics to be distributed to all the women attending to the clinic is of great value which is prepared in simple Arabic language.

2. Reinforce instruction about proper management of minor discomforts via leaflet, which must be accurate, clear, and up-to-date and illustrated with pictures whenever possible to help illiterate women.

3. As the nurse and midwife as a key person in antenatal education have a crucial role in this context. She should be able to correct misinformation about harmful practices to relieve minor discomforts and implementing antenatal educational sessions to women in a simple, direct and effective manner in different antenatal settings. So, in-services training programs, refreshing courses, seminars, and conferences should be provided to upgrade nurses practical and intellectual knowledge about minor discomforts during pregnancy and proper measures to relieve it, to help them perform their educational role effectively.

4. Traditional birth attendants already form a considerable part of the basic core of primary health workers for the majority of the rural population in many developing countries. There is great regional variation in the practices of TBAs, some are being beneficial, and others are harmful. Therefore they should be trained and prepared in the field of health education in order to carry out effective health practices.

5. Encourage outreach health education and home visiting programs for picking up pregnant mothers and refer them to antenatal clinics. Also, conducting home visits for women who had dropped out of their antenatal follow-up visits.

\section{References}

[1] Murray, I., \& Hassall, J. (2014). Change and adaptation in pregnancy. In Marshall, J., \& Raynor, M. (Eds.), Myles textbook for midwives (16th ed., pp. 143-177). Edinburgh: Churchill Livingstone Elsevier.

[2] Deklavaa, L., Lubinaa, K., Circenisa, K., Sudrabaa, V., \& Millerea, I. (2015, 6th). World conference on Psychology Counseling and Guidance, 14-16 May. Causes of anxiety during pregnancy. Procedia-Social and Behavioral Sciences, 205, 623-626. https://doi.org/10.1016/j.sbspro.2015.09.097

[3] Kang, Y., Yao, Y., Dou, J., Guo, X., Li, S., Zhao, C., ... Li, B. (2016). Prevalence and Risk Factors of Maternal 6. Anxiety in Late Pregnancy in China. Int. J. Environ. Res. Public Health, 13(468), 1-11. https://doi.org/10.3390/ijerph13050468

[4] Almalik, M., \& Mosleh, S. (2017). Pregnant women: What do they need to know during pregnancy? A descriptive study. Women and Birth: Journal of the Australian College of Midwives, 30(2), 100-106. https://doi.org/10.1016/j.wombi.2016.09.001

[5] Hassan, H., Sobhy, S., Rakha, E., El-Khayat, I. (2019). Traditional Practices among Rural Women to Relieve Their Common Pregnancy Minor Discomforts: A Descriptive Study. Medical Science \& Healthcare Practice, 3(2), 56-90. https://doi.org/10.22158/mshp.v3n2p56 
[6] Hassan, H., Zahran, K., Youness, E., \& Nady, F. (2015). Pregnant Women's Awareness, Intention and Compliance regarding Folic Acid Usage for Prevention of Neural Tube Defects According to Health Belief Model in Beni-Suef City. Pyrex Journal of Nursing and Midwifery, 1(3), 13-26.

[7] Mohamed, W., \& Hassan, H. (2020). Effect of Instructional Supportive Guideline for Improving Women's Awareness towards Endometriosis. American Journal of Nursing Research, 8(1), 38-47. https://doi.org/10.12691/ajnr-8-1-5

[8] Gamel, W., Genedy, A., \& Hassan, H. (2020). Impact of Puerperal Sepsis Self-Care Nursing Guideline on Women's Knowledge and Practices. American Journal of Nursing Research, 8(2).

[9] Hassan, H., Nady, F., Youns, E., \& Zahran, K. (2016). Call for Change Level of Knowledge, Awareness and Attitude to Follow A High Folate Diet Among Pregnant Women. IOSR Journal of Nursing and Health Science, 5(1), 93-100. https://doi.org/10.9790/1959-051293100

[10] Said, A. (2016). Effect of counseling intervention on women's knowledge, practices and lifestyle of fetal well-being among Primigravida. International Journal of Nursing Science, 6(4), 87-93

[11] Farg, D., \& Hassan, H. (2019). Study Hyperemesis Graviderum Requiring Hospital Admission during Pregnancy: Effect of Nursing Implication on Its Progress. American Journal of Nursing Research, 7(3), 328-341. https://doi.org/10.12691/ajnr-7-3-14

[12] Farg, D., \& Hassan, H. (2020). Obstetric Outcomes for Teenage and Adult Pregnancy: A Comparative Study. Nursing \& Care Open Access Journal, 7(1), 1-16.

[13] Farag, D., \& Hassan, H. (2019). Maternal Postpartum Sleep disturbance and Fatigue: Factors Influencing. ARC Journal of Nursing and Healthcare, 5(2), 33-46. http://dx.doi.org/10.20431/2455-4324.0502005

[14] Hassan, H., El-Sadek, A., \& Ali, L. (2019). Effect of Three Different Nursing Interventions on Intestinal Motility and Women's Satisfaction Post-Cesarean Section Birth. American Journal of Nursing Research, 7(6), 932-941. https://doi.org/10.12691/ajnr-7-6-4

[15] Reader, S., Martin, L., \& Koniak, D. (1992). Maternity Nursing (17th ed.). J.B. Lippincott Com, New York, pp. 421-424.

[16] Chamberlain, G., \& Pearce, J. (1992). Lecture notes on obstetrics (6th ed.). Blackwell scientific publications, London, p. 53.

[17] Chan, Ch., Lee, A., Lam, S., Lee, Ch., Leung, K., Koh, Y., \& Tang, C. (2013). Antenatal anxiety in the first trimester: Risk factors and effects on anxiety and depression in the third trimester and 6-week postpartum. Open Journal of Psychiatry, 3, 301-310. https://doi.org/10.4236/ojpsych.2013.33030

[18] Deklavaa, L., Lubinaa, K., Circenisa, K., Sudrabaa, V., \& Millerea, I. (2015, 6th). World conference on Psychology Counseling and Guidance, 14 - 16 May 2015: Causes of anxiety during pregnancy. Procedia Social and Behavioral Sciences, (205), 623-626. https://doi.org/10.1016/j.sbspro.2015.09.097

[19] Hassan, H. (2016). Infertility profile, psychological ramifications and reproductive tract infection among infertile women, in northern Upper Egypt. Journal of Nursing Education and Practice, 6(4), 92-108. https://doi.org/10.5430/jnep.v6n4p92

[20] Beischer, N., \& Mackay, E. (1989). Obstetrics and the new born (2nd ed.). Bailliere Tindall Com, London, p. 11.

[21] Hassan, H., Said, S., \& Hassanine, Sh. (2017). Disparities of Prevalence and Causes of Maternal Antenatal Anxiety among Primigravida Pregnant Women in Egypt. American Research Journal of Nursing, 3(1), 1-15. https://doi.org/10.21694/2379-2922.17014

[22] Nasr, E., Hassan, H., \& Sheha, E. (2016). Psychological Consequences of Hypertensive Disorders among Pregnant Women. Scientific Research Journal, 4(9), 1-8.

[23] Hassan, H., Saber, N., \& Sheha, E. (2019). Comprehension of Dyspareunia and Related Anxiety among Northern Upper Egyptian women: Impact of Nursing Consultation Context Using PLISSIT Model. Nursing \& Care Open Access Journal, 6(1), 1-19. https://doi.org/10.15406/ncoaj.2019.06.00177

[24] Gamel, W., Hassan, H., El-ezazy, A. (2019). Male Infertility and Psychological Repercussions: A Neglected Problem in Northern Upper Egypt. International Journal of Studies in Nursing, 4(4), 1-26. https://doi.org/10.20849/ijsn.v4i4.654 
[25] Zung, W. (1971). A rating instrument for anxiety. Psychosomatics, 12, 371-379 (Reprinted with permission from Psychosomatics). https://doi.org/10.1016/S0033-3182(71)71479-0

[26] Kang, Y., Yao, Y., Dou, J., Guo, X., Li, S., Zhao, C., ... Li, B. (2016). Prevalence and Risk Factors of Maternal Anxiety in Late Pregnancy in China. Int. J. Environ. Res. Public Health, 13(468), 1-11. https://doi.org/10.3390/ijerph13050468

[27] Hassan, H. (2018). Effectiveness of a structured teaching program on anxiety and perception regarding toxoplasmosis among seropositive pregnant women in Northern Upper Egypt. Clinical Nursing Studies, 6(1), 1-19. https://doi.org/10.5430/cns.v6n1p1

[28] Hassan, H. (2016). Call for psychosocial well-being among pregnant women associated with medical disorder in Beni-Suef governorate. IOSR Journal of Nursing and Health Science, 5(2), 81-94. https://doi.org/10.9790/1959-0502048194

[29] Nazik, E., \& Eryilmaz, G. (2014). Incidence of pregnancy-related discomforts and management approaches to relieve them among pregnant women. Journal of Clinical Nursing, 23(11), 1736-50. https://doi.org/10.1111/jocn.12323

[30] Patil1, N., \& Salunkhe, J. (2015). Assessment of Knowledge on Minor Ailments of Pregnancy and Home Remedies. International Journal of Science and Research (IJSR), 4(1), 674-677.

[31] Nun, D., Adesuyi, E., \& Olawoore, S. (2018). Knowledge attitude and practices of pregnant women attending comprehensive Health Centre, Isolo, Ondo State towards Hygienic Practice. International Journal of Tropical Disease \& Health, 30(2), 1-10. https://doi.org/10.9734/IJTDH/2018/40582

[32] Oliveira, S., Fernandes, A., Vasconcelos, E., Ximenes, L., Leal, L., et al.. (2018). Effect of an educational intervention on pregnancy: a cluster-randomized clinical trial. Acta Paulista de Enfermagem, 31(3), 8-291. https://doi.org/10.1590/1982-0194201800041

[33] AbdElhaliem, S., AbdElhad, R., \& Mohamed, A. (2018). Utilization of self-care practice guideline on relieving minor discomfort (ailments) among new pregnant woman. IOSR Journal of Nursing and Health Science (IOSR-JNHS), 7(1), 7-15.

[34] Ayoub, G., \& Awed, H. (2018). Comparative Study between Primigravida and Multigravida Regarding Women's Self-Care Practices for Management of Selected Minor Discomforts. Madridge J Case Rep Stud., 2(1), 1000111. https://doi.org/10.18689/mjcrs-1000111

[35] Abdel, H. A., Makhlouf, E., \& Mohammed, O. (2018). Effect of Antenatal Educational Guidelines on Mother's Knowledge. IOSR Journal of Nursing and Health Science (IOSR-JNHS), 7(2), 21-26.

[36] Indra, V. (2016). Effectiveness of Self Instructional Module (SIM) on Knowledge Regarding Selected Aspects of Safe Motherhood among Primigravida Women in Selected Hospitals, Puducherry. International $\begin{array}{llll}\text { Journal of Nursing Education and Research, 4(3), 2454-2660. } & \text {. }\end{array}$ https://doi.org/10.5958/2454-2660.2016.00048.X

[37] Ahmed, M. (2015). Effect of intervention Guidelines on self-care practices of pregnant women with urinary tract infection. Life cience Journal, 12(1), 114-124.

[38] Latha, P., \& Indira, S. (2016). Effectiveness of IEC (Information, Education \& Communication) package on knowledge regarding minor ailments of pregnancy and its management among antenatal mothers at NMCH, Nellore, A.P. International Journal of Applied Research, 2(10), 593-596.

\section{Copyrights}

Copyright for this article is retained by the author(s), with first publication rights granted to the journal.

This is an open-access article distributed under the terms and conditions of the Creative Commons Attribution license (http://creativecommons.org/licenses/by/4.0/). 